
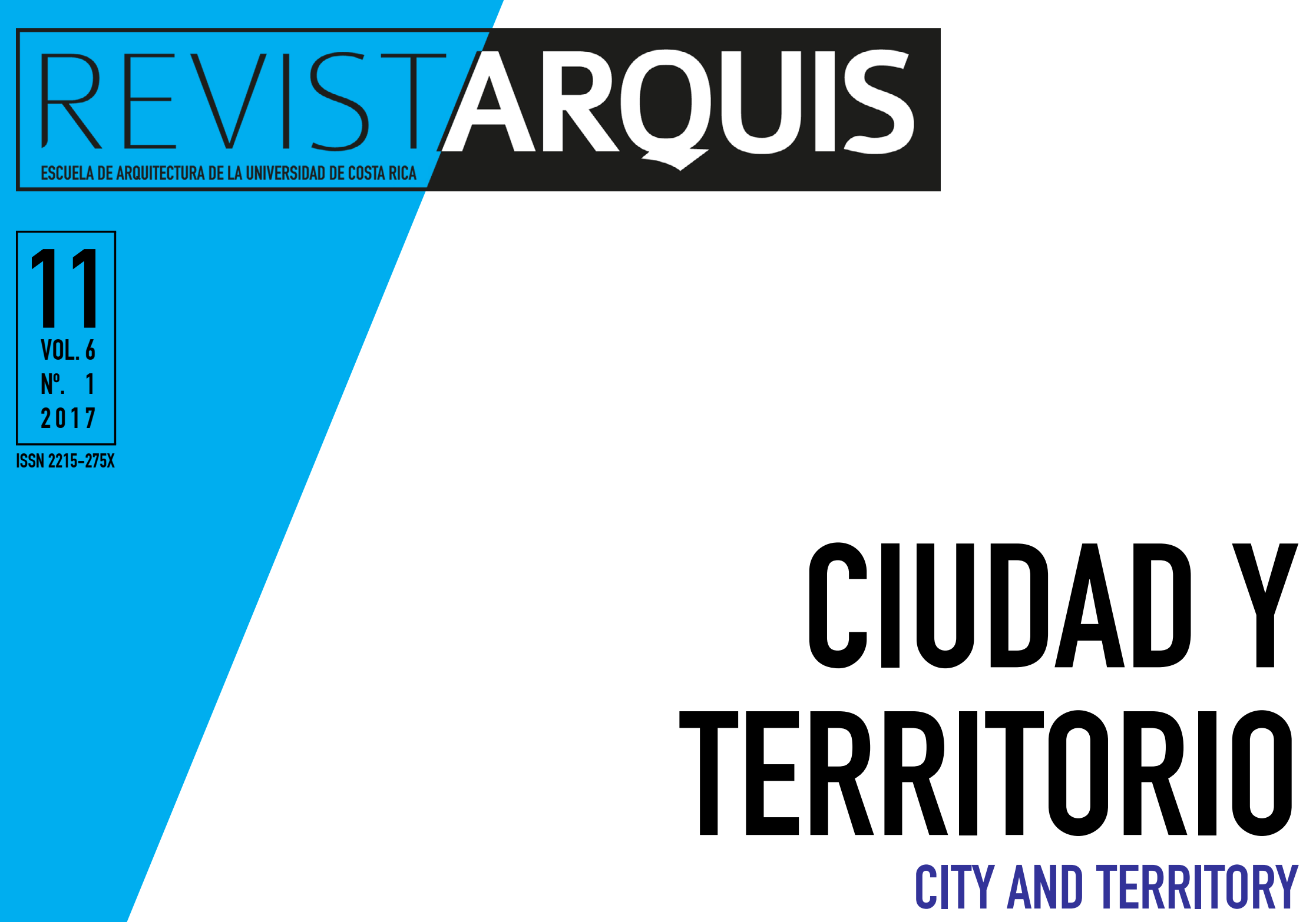

1_ ¿Gentrificación latinoamericana? Apuntes para su discusión
Luis Alberto Salinas Arreortua
Ensayo | 1-10

2_ Los estudios culturales y la construcción social del patrimonio cultural Rosa Elena Malavassi Aguilar

Investigación | 11-19

3_ Un centro cívico o el réquiem del patrimonio urbano costarricense Marcela Muñoz Muñoz

Ensayo | 20-28

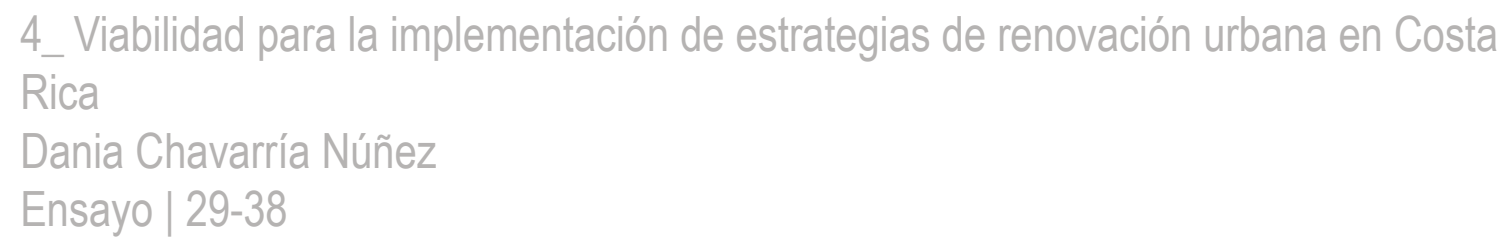

4_Viabilidad para la implementación de estrategias de renovación urbana en Costa Rica

Dania Chavarría Núñez

Ensayo | 29-38
5_Estado actual y perspectivas de la legislación urbana en Costa Rica Jessica Martínez Porras
Reflexión | 39-47




\title{
Un centro cívico o el réquiem del patrimonio urbano costarricense
}

\author{
Marcela Muñoz Muñoz
}

\section{Resumen}

Ensayo

Invitada nacional

Universidad de Costa Rica

email: marcela.munozmunoz@ucr.ac.cr

Recibido: 14 de enero del 2016

Aceptado: 31 de marzo del 2017

Se ofrece una honra póstuma a la arquitectura pública de la capital costarricense, San José, como modelo de ciudad nacional. Por medio del estudio de una discusión legislativa se aborda la conveniencia de dotar al país de un centro cívico nacional, la cual favorece la [in]comprensión de un urbanismo incipiente, anterior a 1970, década en la cual se consolida el derecho urbanístico. Mediante el símil del réquiem, la historia del derecho urbanístico reclama la inutilidad de soluciones jurídicas por salvar valiosas edificaciones que vieran la luz en la conformación del Estado Nacional, durante los siglos XIX y XX. El afán de modernidad de Costa Rica requiere que el derecho urbanístico halle nuevas formas de entender el patrimonio urbano.

Palabras clave: Derecho urbanístico; historia; patrimonio arquitectónico; patrimonio urbano

Abstract

This article offers a posthumous honor for public architecture of the Costa Rican capital, San José, as a national model of a city. The study of the discussion contained in certain legislative acts around the convenience to give the country a National Civic Center, [do not] favors the understanding of an emerging Urban Planning before 1970's, the "legal" decade for the Urban Law. By using the analogy of the requiem, the History of Urban Law demands the futility of legal solutions to save valuable buildings that were born in the formation of the National State, during the 19th and 20th centuries. The Costa Rica's quest for modernity claims for new ways where Law can understand Urban Heritage.

Keywords: Urban law; history; architectural heritage; urban heritage

\footnotetext{
Marcela Muñoz Muñoz

Historiadora y Abogada por la Universidad de Costa Rica. Maestra en Derecho Público por la Universidad de Toulouse I Capitole, Francia. Posee formación en Gestión de Patrimonio Urbano en la Universidad de Sevilla, España. Profesora Instructora en las Cátedras de Historia del Derecho y Derecho Romano de la Facultad de Derecho de la Universidad de Costa Rica.
} 


\section{Un centro cívico como símbolo del nacionalismo}

llustración 1. Plano de la ciudad de San José hacia 1960. El área en cuestión corresponde al número 2, hacia el Este. Fuente. Vega, 1982. esde el año 1955, el Departamento de Urbanismo del Instituto Nacional de Vivienda y Urbanismo (INVU) propuso el diseño y construcción de un Centro Cívico Nacional, el cual no logró concretarse por falta de voluntad política ${ }^{1}$ en la década de 1950. La necesidad de este Centro respondería a un concepto sistémico de ciudad como organismo vivo, como una continuidad del "deseo de los gobernantes de impresionar a ciudadanos y visitantes con magníficos conjuntos de edificios y monumentos desplegados alrededor de hermosos parques y servidos por majestuosas avenidas" (Jenkins et al., 1956)². El tratamiento que se dará al concepto de patrimonio urbano puede ubicarse, según este diseño, solamente bajo la variable cultural. La ilustración 1 muestra el cuadrante de la ciudad de San José aproximadamente en 1960.

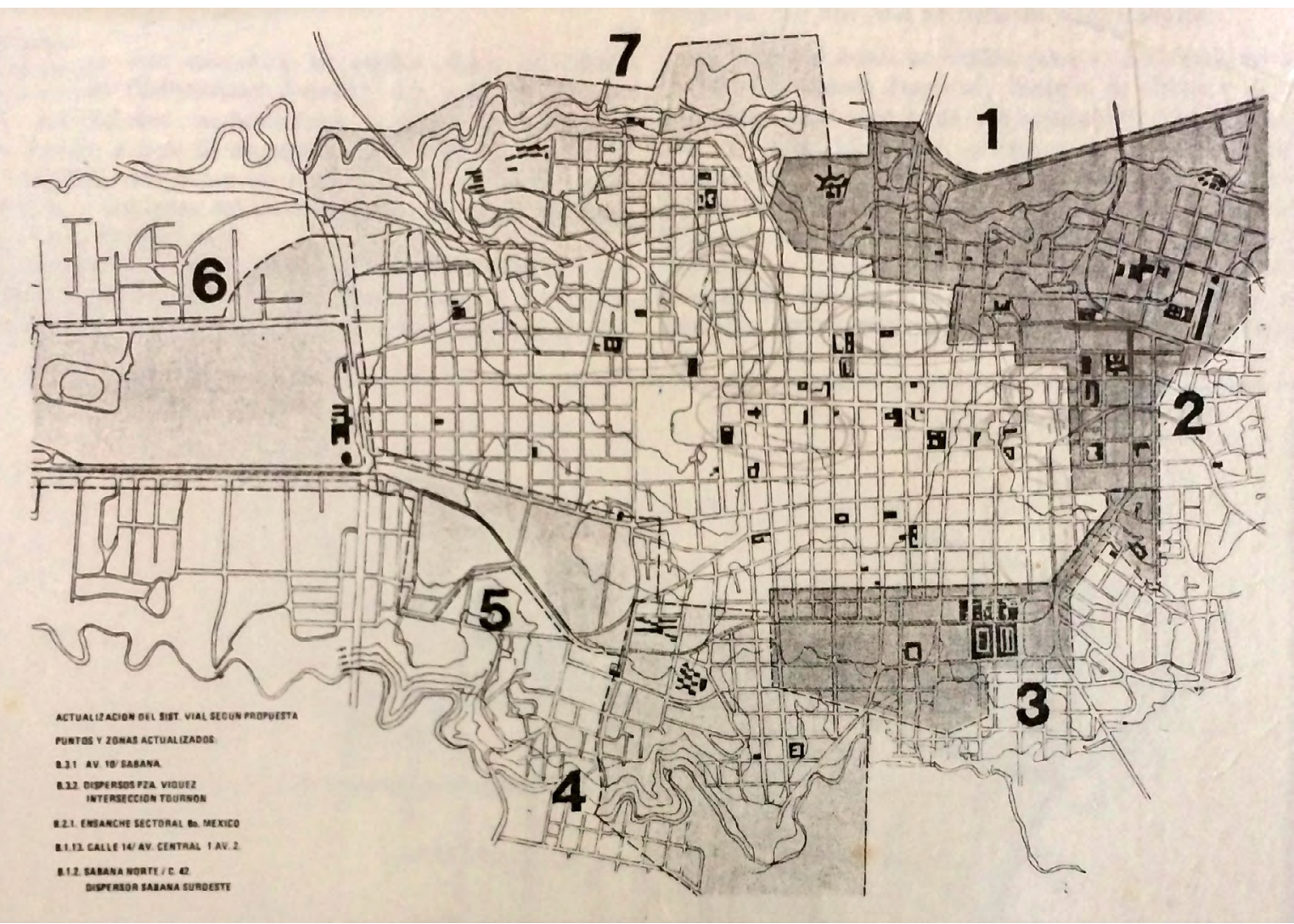

De esta suerte, a finales de la década de 1960, la Asamblea Legislativa de Costa Rica decide el futuro (derribo o permanencia) de dos inmuebles icónicos de la capitalina ciudad de San José; fatídica para la antigua Biblioteca Nacional de Costa Rica, favorable para el Cuartel Bellavista, actual Museo Nacional, con la idea de conformar el componente cultural del Centro Cívico ${ }^{3}$. Con respecto a la Biblioteca Nacional, se creó dentro de la liberal Universidad de Santo Tomás y más tarde se ubicó de manera independiente en la esquina sureste del Mercado Central de San José. Así, en 1899 se trasladó a una casona colonial en la esquina de Avenida $1^{\circ}$ y Calle 5 (señas actuales). Más tarde fue derruido 4 para dar paso a un edificio neoclásico, que abrió sus puertas en 1907 y las cerró en 1969, cuando, más moderna, integraría el Centro Cívico.

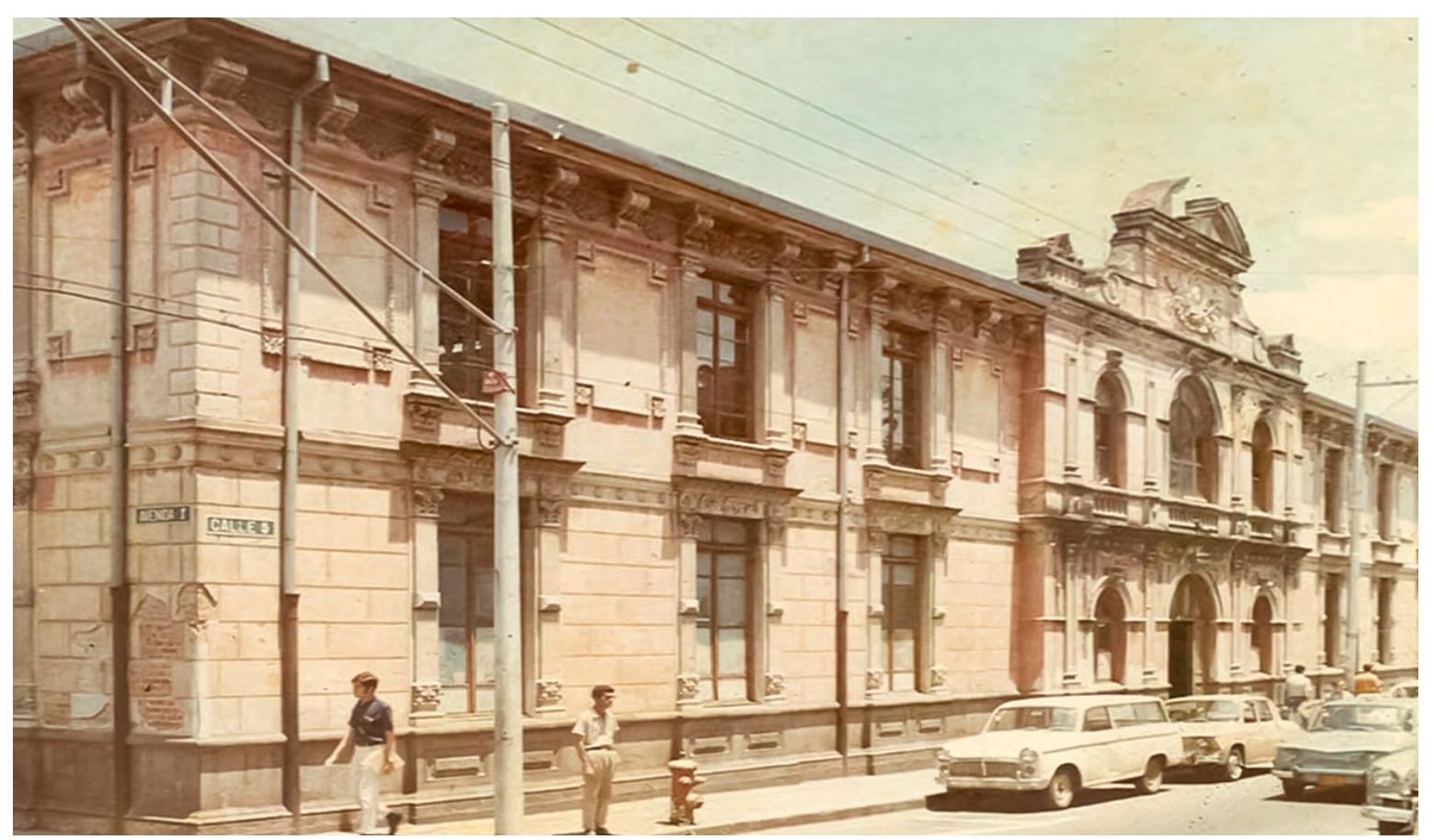


$5 \quad$ José Figueres Ferrer (1906-1990). Tres veces Presidente de Costa Rica en los períodos de 1948-1949, 1953-1958 y 1970-1974. Por su trascendencia política como caudillo se ha llamado a su legado Figuerismo y figueristas a sus seguidores. En ese sentido, se instaura en Costa Rica lo que se conoce como Segunda República. Véase Muñoz, M. (1990). El estado y la abolición del ejército, 1914-1949. Editorial Porvenir. $6 \quad$ Artículo 1.- "El Museo Nacional es el centro encargado de recoger, estudiar y conservar...sus reliquias históricas y arqueológicas..." según Ley NN1542 del 7 de marzo de 1953. Anterior a este período, cuando se propuso en el decreto $\mathrm{N}^{\circ} 5$ del 18 de enero de 1888 su organización, se refería a curiosidades históricas.

$7 \quad$ Vale aquí traer a colación el hecho de que la Asamblea Constituyente en 1949 estimó oportuno consagrar un artículo que protegiera las bellezas naturales de la Nación (lo único bonito que al parecer por entonces se encontraba) y así se escribió en el artículo 89 de la Constitución

Política de 7 de noviembre. A pesar de consagrarse allí el término de patrimonio y la procura de su conservación y desarrollo, la sede de esa Asamblea fue demolida por orden de Figueres. El mismo edificio donde por primera vez se reconociera constitucionalmente nada auguró de su desahucio (Fernández, 2010).

8 Todos los documentos aquí citados se encuentran contenidos en el Expediente №2970. Sin embargo, por razones de orden archivístico y para facilitar la lectura, no fue posible concordar la foliación con la secuencia temporal inserta en la carpeta. Encuéntrese aquí la cita individual de cada documento.

$9 \quad$ Ley de Patrimonio Histórico Cultural y Artístico de la Nación №5397 de 8 de noviembre de 1973.

10 En realidad, en la Costa Rica anterior a 1970, no existe una delegación clara en la materia "cultura", sino medidas ad hoc alrededor del Ministerio de Educación y, en específico, a la Universidad de Costa Rica.

11 El estudio de lo urbanístico puede teorizarse en Costa Rica a partir de los años setenta del siglo anterior, desde el punto de vista jurídico, por la existencia de leyes que lo reconocen, pues anteriormente se relegaba a una competencia de una institución autónoma, el INVU creada en 1954. Anterior a esta época, puede intentarse más bien una historia urbana con ordenanzas municipales y otras disposiciones legales, aunque posiblemente la verdadera luz la arrojará una arqueología urbana por el predominio de ruinas o yacimientos bajo tierra. Desde el punto de vista jurídico, esos estudios se centran en una serie de normas sobre el territorio, cuyo fundamento se encuentra en la planificación urbana gracias a la Ley de Planificación Urbana N ${ }^{\circ} 4240$ de 15 de noviembre de 1968. En ese decenio este país contaría, además, con un Código Municipal, Ley $\mathrm{N}^{\circ} 4574$, de 4 de mayo de 1970 marco legal para los municipios, quienes tienen a su cargo la toma de decisiones en torno a la regulación territorial. Nótese que los instrumentos legales de la planificación son los planes, nacional de desarrollo o reguladores locales. Adicionalmente las medidas legales se componen de licencias,
En cuanto al llamado Cuartel Bellavista, finalizado hacia 1930 con el fin de albergar las fuerzas militares de Costa Rica, constituye un emblema patrio. Efectivamente, el 11 de octubre del año 1949 y por Decreto N749 de la Junta Fundadora de la Segunda República se dictaminó que el uso de la edificación no representaría más la guerra. Su torreón fue simbólicamente derribado por José Figueres ${ }^{5}$ el $1^{0}$ de diciembre del año 1948 anterior, en un acto presidido por su Ministro de Educación, Uladislao Gámez. El edificio se convierte en reliquia nacional ${ }^{6}$ al destinar un inmueble para otro fin del que fuera concebido: la conversión de un cuartel en un museo (Corrales y Cubero, 2005). Además, Figueres enunció dos grandes baluartes de la "cultura" nacional: la naturaleza y la arqueología, excluyendo las características inmateriales propias del inmueble?.

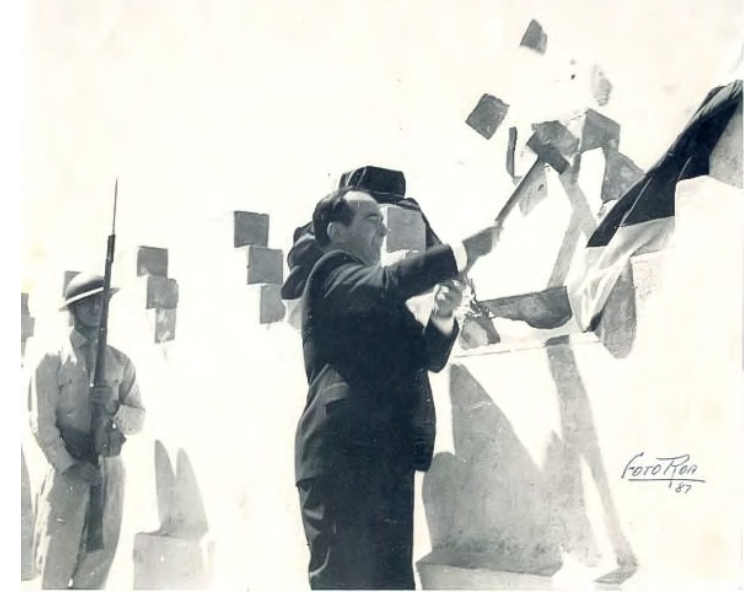

Ilustración 3. Figueres derribando el torreón del Museo. Fuente: archivonacional.go.cr

Lo anterior justifica una amplia discusión legislativa en torno a la necesidad estratégicapolítica de un espacio cultural citadino; una emblemática manzana ubicada en San José. Este conjunto de un lado, solucionaría la dispersión de los edificios sede de las oficinas públicas josefinas y evitaría el gasto público de los respectivos arrendamientos y, por otro, concentraría un albergue cultural, núcleo de los valores cívicos nacionales. De las opiniones extraídas del Expediente Legislativo №2970 del 12 de julio de $1967^{8}$ pueden escogerse apreciaciones que salpican lo urbanístico con un tinte histórico, jurídico y político. Histórico porque se mezcla con la identidad nacionalista-abolicionista, coyuntura que antecede la década planificadora, creadora del Ministerio de Cultura y la primera legislación acerca del patrimonio histórico9

De tinte jurídico, por referirse a las competencias, la posibilidad de actuación dentro de un marco legal donde las decisiones administrativas en torno a la ciudad se hallan dispersas y no siempre se inclinan a favor de la cultura ${ }^{10} . Y$ apreciaciones de tinte político, pues trata de un debate a lo interno de las comisiones legislativas donde se discuten los proyectos de ley como fuera el contenido en el tal Expediente. El centro cívico privilegia en el Congreso un sentimiento nacionalista por encima de criterios técnicos en torno al patrimonio arquitectónico urbano. Es decir, en Costa Rica ha primado un ideal de progreso sobre la conservación edilicia.

El recurso archivístico legislativo sugiere que la falta de un marco legal urbanístico contribuye a la vulnerabilidad del patrimonio urbano costarricense, notoriamente de la arquitectura pública o edilicia. Lo dicho apunta a buscar, en las decisiones administrativas o políticas, una guía para la comprensión de la actual ciudad y de una especie de colisión normativa entre las competencias, el urbanismo y un incipiente derecho urbanístico ${ }^{11}$. Mediante el símil del réquiem, se ensaya una honra póstuma a la arquitectura urbana capitalina en un ejemplo del urbanismo costarricense: el Proyecto de Ley para la creación de un Centro Cívico, Expediente №2970 de 12 de julio de 1967, el cual se yergue paradigmático en una década donde el derecho público y el urbanístico se encontraron -y acaso colisionaron- con las ideas de nación y modernidad.

El Expediente №2970 permite vislumbrar una genealogía normativa del patrimonio arquitectónico urbano, permitiendo [en una suerte de iter obitus] indagar ¿por qué el patrimonio urbano en Costa Rica se traduce como un proceso de legitimación política más que en decisiones concertadas y coordinadas proyectadas en el tiempo? Para guiar la respuesta, en un primer apartado se tratará el tema de las competencias en materia de patrimonio urbanístico, en una época donde se enfrentan las normas, la legalidad y la culturalidad. La segunda se concentra en la superposición del nacionalismo sobre el urbanismo, con base en criterios de dignidad para albergar la institucionalidad pública. 
Finalmente, se intentará subrayar que el Proyecto de Centro Cívico ejemplifica un modelo de toma de decisiones alrededor del patrimonio urbano y quizás favorezca la comprensión y apreciación actual del patrimonio urbano costarricense.

permisos y otros actos administrativos del gobierno local, sin perjuicio de otra normativa sobre el uso del suelo que sea aplicable a los casos concretos como ambientales, forestales, agrarios, etc. Debe aclararse, que las propias fuentes aquí utilizadas son omisas en la materia municipal, y ni qué decir de la ambiental, por lo tanto no se integran en esta discusión.

12 Ley de creación del Ministerio de Cultura No4788 de 7 de julio de 1971.

13 Tal honor parece merecer la referencia al himno estudiantil "Gaudeamus Igitur". El título originario de la obra es "De brevitate vitae" y fue utilizado en las universidades de Alemania en el Siglo XVIII, aunque su autoría desconocida puede sugerir que existían algunos versos en el Siglo XIII. En Costa Rica se entona como la Marcha Universitaria en los actos oficiales de la Universidad de Costa Rica.

14 El Decreto-Ley que traspasa la administración a una junta administrativa dependiente del Ministerio de Educación expone cómo la Universidad y el Poder Ejecutivo han llegado a un acuerdo, por lo tanto, la Universidad renunciaba a cualquier alquiler o enriquecimiento por el alojamiento del inmueble.

15 Véase Fernández, A. (2010) y Ruiz, N (1973)

16 Artículo 84.- "La Universidad de Costa Rica es una institución de cultura superior que goza de independencia para el desempeño de sus funciones y de plena capacidad jurídica para adquirir derechos y contraer obligaciones, así como para darse su organización y gobierno propios. Las demás instituciones de educación superior universitaria del Estado tendrán la misma independencia funcional e igual capacidad jurídica que la Universidad de Costa Rica. El Estado las dotará de patrimonio propio y colaborará en su financiación. (Así reformado por el artículo único de la ley №5697 de 9 de junio de 1975).

$17 \quad$ La exposición del Proyecto se refirió a la Universidad: "Si bien es cierto que por Decreto Ley N0749 se traspasó a la Universidad de Costa Rica, el antiguo Cuartel Bellavista y se le destinó a servir de alojamiento al Museo Nacional, estamos seguros de que las autoridades de nuestra más alta Casa de Estudios, habrán de comprender la importancia de que en un terreno suyo se construyan edificaciones como las que se proponen y cuyos fines se compaginan tan bien con los servicios de la Universidad de Costa Rica". O sea que hubiera resultado tautológico preguntar por la salvaguardia cultural costarricense.

18 Como nota aclaratoria nótese que el

Consejo Universitario había aceptado el traspaso en Sesión del 19 de mayo de 1952, modificada por la del 16 de junio del mismo año. Básicamente, la Universidad no podía asumir financieramente los museos nacionales (el plural se refiere al Parque Simón Bolívar) y por tanto la Asamblea Legislativa dictó el nuevo poseedor (nunca un nuevo propietario).

19 Publicado en La Gaceta No162 del 19 de julio de 1967.

20 Oficio NoR-1019-67 de 30 de junio de 1967. Carta del Rector Carlos Monge Alfaro a los representantes de la Comisión de Asuntos Sociales donde expone los acuerdos de la Sesión №1580 (sin fecha) del Consejo Universitario y sus acuerdos en torno al proyecto de Centro Cívico. Salvo que

\section{Gaudeamus Igitur: la cuestión sobre las competencias}

Este expediente permite explorar la alianza histórica entre la materia cultural y la educación pública [superior]; en una etapa donde lo relativo a la cultura correspondía al Ministerio de Educación, cuya desperdigada institucionalidad -y competencialidad-, no fue aclarada hasta que en 1971 se crease un Ministerio de Cultura ${ }^{12}$. Habida cuenta de esta ausencia, nótese que desde 1949, sin embargo, la Universidad de Costa Rica, creada en 1941, porta por designio constitucional la batuta de la cultura ${ }^{13}$. Se convierte en la heredera tomasina de la primera Biblioteca Nacional y propietaria del inmueble conocido como Cuartel Bellavista ${ }^{14}$.

De esta forma, la biblioteca de Santo Tomás se registra como la primera biblioteca de tipo nacional, aunque el edificio original de la casa universitaria fuera demolido por razones expansionistas ${ }^{15}$. Por aquel entonces, el Ministerio de Educación delegaría competencias a la flamante educación superior costarricense. La Universidad recibió en traspaso los terrenos donde se encontraba el Cuartel Bellavista. Como ente público autónomo a cargo de la cultura "superior"16, la Universidad de Costa Rica poseería una doble personalidad de derecho público y privado, es decir, con capacidad jurídica para adquirir derechos y contraer obligaciones. Por lo tanto, se asignan competencias en materia de cultura a un ente de la educación superior por designio de la propia Constitución y, más aún, dentro de su capacidad jurídica dominical posee el control sobre el destino de un inmueble con fin público.

Pareciera que la doble capacidad jurídica de los entes públicos le permite a la autonomía universitaria una extralimitación justificada, dejando un poderoso propietario ${ }^{17}$, la Universidad, frente a una especie de posesor de buena fe, la Junta Administrativa del Museo Nacional ${ }^{18}$. El propio Rector de la Universidad de Costa Rica, Carlos Monge Alfaro (casualmente nombre de la actual biblioteca universitaria), se dirigió a los señores diputados de la Comisión Permanente de Asuntos Sociales que conocían el Proyecto de Ley ${ }^{19}$, expresando las razones de participación de la institución ${ }^{20}$. Entre éstas, las evidentes "conexiones de índole cultural que existen entre el Museo y la Biblioteca por un lado y la Universidad por otro"; el orador prevenía de manera positiva que "no surgirán conflictos entre el derecho de propiedad de la Universidad y la construcción de los edificios por el Gobierno Central".

Monge Alfaro muestra el toque autonomista dando su viso y confirma que el Proyecto le interesaba a la Universidad, no sólo como propietaria sino que, además, la institución debía tomarse en cuenta para "la elaboración del inventario de necesidades, la formulación de bases del concurso arquitectónico y el jurado calificador de los proyectos que se presenten". Más allá del interés universitario en la labor del Museo y la Biblioteca (cultura superior), la Benemérita contaba con "experiencia en el planteamiento de obras de tipo edificativo y con especialistas en campos muy relacionados con ambas instituciones". La opinión de Monge Alfaro se acoge en la Comisión legislativa, a tal punto, que el concurso y sus reglas se discuten en un foro universitario ${ }^{21}$.

En esa discusión se decide rechazar el Proyecto que se había presentado al Congreso. Como la misma carta lo dice, la Universidad estaba a favor de que desapareciera la antigua Biblioteca y el Museo ${ }^{22}$, por ser ella quien podría "proporcionar amplia ayuda a fin de que un proyecto de tal importancia para la vida cultural del país se realice en la forma más satisfactoria". No sorprende entonces que a la Universidad se le reconoció una labor en la elaboración del cartel y un estudio sobre el estado actual de las edificaciones. La cuestión dominical, es decir, el derecho del propietario que había cedido la "posesión" por vía legal al Museo, fue considerada por el Proyecto de Ley. De esta suerte, un propietario público-autónomo en ejercicio de derecho privado, pero con un fin público, dictaría las bases del concurso, revisaría y escogería la oferta y además, emitiría un criterio de viabilidad cultural. 
se indique lo contrario, las citas de este apartado se extraen del Expediente, en el cual resulta difícil conocer la foliación.

21 Ver más adelante la referencia a este foro. 22 "Es innegable la conveniencia del proyecto sugerido, sobre todo en cuanto propone a construcción, en la manzana mencionada, de los edificios del Museo Nacional y de la Biblioteca Nacional", desestimó el Rector la inclusión del Ministerio de Educación Pública por una cuestión de crecimiento futuro.

23 Para este momento, el marco público era regulado por la Ley de Administración Financiera de la República №1279 de 2 de mayo de 1951. No existen aún la Ley General de la Administración Pública (1978) ni el Código Municipal (1974), qué decir de la Ley de Contratación Administrativa (1995)

24 En palabras del presidente de la Junta Administrativa, Jaime Solera Bennett: "Es cierto que la Universidad es la dueña del Museo, pero el Museo está regido por el Poder Ejecutivo, por el Ministerio de Educación Pública y tiene una Junta que mal que bien cumple con sus funciones, que conviene oír [sic] la opinión de la Junta pareciera que así es, porque después de que el proyecto estuvo en el Plenario ha venido a esta Comisión, la misma tuvo la gentileza de convocarnos para oír [sic] nuestra opinión. De manera que aunque el dueño de la propiedad sea otro, el que la administra es un grupo diferente." Adicionalmente menciona Solera que la Universidad había expresado su intención de convertir el Museo en un laboratorio (Ídem, ff.4-5).

25 Permítase aquí una continuación del titulado anterior para crear una especie de partitura del Réquiem, a propósito del Expediente №2970 en cuestión.

26 A propósito de la demolición de la antigua Casa de Enseñanza de Santo Tomás se expresó Gutiérrez: "Si el país ha podido alojar dignamente a uno de los poderes de la República, como es la Corte Suprema de Justicia, debe continuar ese esfuerzo para alojar...dignamente a instalaciones básicas de la cultura nacional." (Sesión ordinaria de la Comisión Permanente de Asuntos Sociales N49 de las $14 \mathrm{~h}$ del catorce de setiembre de 1967 ff.2-3). Resulta además interesante dentro del pensamiento del Decano dos postulados filosóficos: la identidad de funciones entre la Biblioteca y el Museo y el nuevo sentido del Gobierno de la República, en un plazo de diez años [¿platónico?] (Véase la exposición de motivos del Expediente citado supra y la Sesión N49, ídem)

27 Podría pensarse que el patrimonio urbano costarricense ha estado influenciado por modelos extranjeros sin atender a las condiciones y realidad locales. Obsérvense al respecto las opiniones de los señores diputados con respecto al Museo mexicano. Así para Gutiérrez: “...Yo no creo que los museos para ser buenos tienen que estar en edificios viejos, para mi [sic] el mejor museo del mundo en estos momentos, por lo menos de los que tengo el gusto de conocer, es el Museo Antropológico de México, que es un edificio de tres plantas, que representa la arquitectura moderna puesta al servicio de un museo y no creo que exista o por lo menos no conozco, ningún museo más moderno en su concepción y mejor diseñado como Museo que el Antropológico de México.
Así se propuso en el Proyecto, amplia consideración claro, de sus posibilidades de entrar en el concurso como oferente ${ }^{23}$. Las vastas opciones universitarias exudan una neblina turibular de control de la labor legislativa y administrativa; una superioridad sobre la viabilidad cultural y urbanística de un proyecto nacional cuya última decisión correspondía al Ministerio de Educación como administrador del Museo (por medio de una Junta Administrativa ${ }^{24}$ ). El conflicto de competencias no parece ser evidente en el ambiente político; la problemática en torno al patrimonio urbano transcurre bajo un tintero cultural-nacional-universitario y no en uno de urbanismo, menos una materia del derecho urbanístico.

\section{URBS URBIS OPUS 2970: Cuestión de fin público25}

El concepto de ciudad, heredado de la tradición romana (urbs urbis), conlleva no sólo criterios urbanísticos, también está revestido de un halo de dignidad y grandeza. En el caso costarricense, el aura de grandeza y dignidad de la urbe parecen ser una preocupación de la política y así lo refleja el marco de la creación de un centro "cultural": el Proyecto para la creación de un Centro Cívico Nacional. El objetivo de la propuesta se dirigía a "centralizar" en un conglomerado urbano -una manzana- el Museo Nacional de Costa Rica, la Biblioteca Nacional de Costa Rica y nada menos que el Ministerio de Educación Pública. Se arguyó que el Museo ocupaba solamente un 25\% del terreno total, pudiendo edificarse en el restante $75 \%$, con lo cual su inclusión fue descartada.

Ante la Comisión de Asuntos Sociales de la Asamblea Legislativa, la batuta empuñada por los diputados Carlos J. Gutiérrez y Carlos F. Aguilar pulsaba por convertir el Cuartel Bellavista en un "bibliomuseo" en un proyecto integrado, y así lo defendían. Sorprenderá que el entonces Decano de la Facultad de Derecho -Gutiérrez- encabezara la idea de la integración en un inicio y más avanzada la discusión, se inclinara por la demolición ${ }^{26}$ En cuanto al inmueble de la Biblioteca, se refiere a la funcionalidad y no a su edificio, elogiándola como "elemento esencial para la formación cultural del pueblo" y más aún, un medio para fomentar la lectura y la formación "de las clases dirigentes del país". Como la suerte de la Biblioteca ya estaba echada, se entiende por qué el expediente debate en torno al tema museístico.

Gutiérrez opinaba que el edificio del Museo no tenía ninguna tradición y que daría lo mismo botarlo que no botarlo (argot tico para la demolición). Insistía Gutiérrez que Costa Rica necesitaba un museo de clase mundial y presentaba lo que a su juicio representaba el mejor modelo a seguir por este país. La opinión compartida por su colega Aguilar apuntaba a que el único museo de esta categoría estaba en México: el Museo de Antropología e Historia. Tal vez obnubilados por la grandeza del conjunto Chapultepec, los señores diputados dejen notar que en Costa Rica se ha optado por la importación de modelos o soluciones urbanísticas, y no por un desarrollo autónomo ${ }^{27}$.

Las opiniones de los diputados reflejan el pensamiento político costarricense de la época en torno al patrimonio arquitectónico urbano. Se extraen aquí algunos fragmentos que contribuyan a comprender la importancia de los conceptos de dignidad, grandeza y progreso, para la planificación de finales de los sesenta. De esta forma, el ala integracionista (por un bibliomuseo) contaba también con el apoyo del Diputado Zamora Jiménez, quien propuso que un piso fuera museo y el otro, biblioteca (el de "arriba"). Estimaba Zamora innecesaria tanta discusión; para él, las técnicas de demolición estaban tan avanzadas, que no supondría un gran costo para el Gobierno ${ }^{28}$.

Conoció también la Comisión de Asuntos Sociales una voz disidente en la postura de la Junta Administrativa del Museo Nacional, presidida por Jaime Solera Bennett ${ }^{29}$. La Junta asume una opinión distinta a la de los diputados, en torno a los problemas del patrimonio mueble e inmueble. Solera explica a los miembros de la Comisión las expectativas de crecimiento que tenía el Museo Nacional: ampliar la sala de arqueología y encontrar cabida al muestrario de la plástica costarricense. Es decir, visualizar un museo inmerso en un modelo en torno al patrimonio como un bien mueble o una reliquia milenaria, centuria al menos. Resulta notorio que este destacado coleccionista incorpore a la discusión costarricense "novedosos" criterios a favor de la ciudad capital, de la ciudad, 
En ese caso la arquitectura moderna ha venido a solucionar los problemas y a hacer resaltar los tesoros que puedan existir en el Museo en forma mejor que lo que podría hacerse en un edificio que fue diseñado para cuartel". El diputado Aguilar por su parte considera "...necesario solventar y pensar en hacer un Museo que verdaderamente funcione como Museo, como verdadero laboratorio, como verdadera sala de investigaciones,

exposiciones [sic] conferencias al tipo que hay en el antropológico de México...El Museo de México tiene dos pisos, lo más tres, pero lo que funciona es la parte baja y la sección de etnología en la parte superior, pero no puede hacerse un Museo vertical, porque no funciona. A la gente no le gusta subir a los Museos...Mi opinión es que el edificio no sirve, no tiene tradición. Desde el punto de vista funcional, el Museo no ofrece ninguna garantía, pese a los grandes esfuerzos que los miembros de la Junta están haciendo en ese sentido [se refiere a donaciones privadas]... Desde el punto de vista funcional, el Museo no ofrece ninguna garantía..." En: Sesión ordinaria de la Comisión Permanente de Asuntos Sociales N49 de las $14 \mathrm{~h}$ del catorce de setiembre de 1967, f.5.

28 Ídem, f.6. También se refirió a la importancia de buscar dinosaurios macana en mano para darle el beneficio de la duda, con esos hallazgos, interesar a los futuros estudiantes con nuevas carreras universitarias.

29 Permítase una pequeña digresión a propósito de Jaime Solera Bennett, pues parecería útil en otra oportunidad estudiar sus ideas en torno al patrimonio. Esto porque si el Palacio Nacional fue derruido (ver supra) para construir la sede del Banco Central de Costa Rica en un espacio apropiado -en el centro de la capital-, resulta curioso que Solera fungiera entonces como directivo del Banco Central y ahora pareciera abanderado de una posición conservacionista de la arquitectura edilicia, pública. También su faceta numismática que le concede su nombre a una Sala especializada en los Museos del Banco Central (construidos de forma subterránea para preservar la monumentalidad del Teatro Nacional) Consúltese el artículo citado "La memoria perdida" (Fernández, 2010).

30 "no es que yo sea gran amigo de lo viejo pero creo que algo debemos mantener de antiguo en nuestra ciudad, como reflejo de una tradición muy interesante, que sí lo es, sino por el aspecto arquitectónico del edificio, porque con una pequeña inversión se puede hacer una belleza" (Sesión ordinaria de la Comisión Permanente de Asuntos Sociales N049, op.cit., f.4)

31 Ibíd., ff.1-2.

32 Aunque no fue posible conseguir la transcripción de dicha actividad para esta publicación, se entiende del Expediente que el programa contaría con la presencia de destacados arquitectos como Rafael García, Carlos Vinocour, José Guillermo Rojas, Hernán Ortiz, Carlos Manuel Ávila, Leonardo Silva y el Ing. Efraím Rojas

33 Oficio dirigido por el Arq. Hernán Arguedas al Lic. Armando Arauz, donde solicitaba exponer los puntos de vista de la Asociación que sería de gran importancia para el éxito del Proyecto.

34 Sesión N49, op.cit., f.7.

35 Ídem.

36 La participación de Jenkins se debe a como la tradición, la arquitectura edilicia, la conservación y la transformación de acuerdo con el fín público ${ }^{30}$

En su informe, Solera resume la situación financiera del Museo, su abandono, su lucha por el autofinanciamiento y la ausencia de fondos por parte del propietario del inmueble. Destaca la remodelación frente a la demolición y el paisajismo como elemento urbanístico. Su perspectiva es clara en cuanto a las finanzas públicas. Podía asumirse el uno sin recurrir al otro; es decir que el Estado puede progresar sin transgredir la arquitectura y los jardines como componentes del espacio urbano. Algunas ideas de este ex directivo del Banco Central, en nombre de la Junta Administrativa, destacan la noción de fines culturales de Archivos y Biblioteca y sus acervos:

"El Museo donde está ubicado es uno de los pocos edificios de tradición que nuestra capital tiene y además sólo para derrirlo [sic] se necesitaría una suma que sería suficiente para ponerlo en condiciones de servir y ser una instalación que podemos mostrarle a cualquier persona del país y fuera de él y que nuestro país no está en ninguna manera en condiciones de hacer gastos más de los necesarios en la construcción de edificios. No hay razón en el caso del Museo para destruirlo, si se trata de una fortaleza, que bien puede repararlo...Comprendemos bien la situación fiscal del país y entonces no podemos qstar [sic] de acuerdo en que se gasten diez millones de colones en derruir un edificio cuyo mantenimiento ha sido recomendado en el Segundo Congreso de Ingeniería y Arquitectura, por considerar que el edificio del Museo es una joya arquitectónica que no debe ser destruída [sic] de ninguna manera... Nuestra opinión es que el proyecto tiene muy buen fin, pero que sería mucho más económico, más lógico, más adecuado a la realidad de Costa Rica el que se pensara en la construcción de un edificio para la Biblioteca y para los Archivos Nacionales pero en otra localización no destruyendo el Museo ${ }^{31}$."

Según Solera, en el foro realizado en la Universidad, los presentes no apoyaban el Proyecto que sí defendía la Asamblea (y claramente el autor), es decir, por la demolición. Esta mesa redonda fue organizada por la Asociación Costarricense de Arquitectos el 13 de setiembre de 1968 y que tuvo como tema la "Trascendencia del proyecto BibliotecaMuseo en la planificación integral del Área Metropolitana ${ }^{32 "}$. Se tiene registro de que la propia Asociación pidió una audiencia a la Comisión legislativa ${ }^{33}$. Súmase a ello que un Congreso de Ingeniería y Arquitectura se declara a favor del antiguo Cuartel, introduciendo por primera vez en la discusión el calificativo de joya para referirse a un inmueble de interés histórico arquitectónico.

Otras voces, como Rafael Luccas Rodríguez y el Arq. Oscar Saborío, defendían al Cuartel Bellavista como el último bastión de tradición josefina. Para Luccas, debía resguardarse el edificio como algo emblemático de una época: "somos un país joven que en sus primeros años no construyó ningún edificio digno de aguantar los embates del tiempo ${ }^{34 "}$. Saborío expone el concepto de preservación del patrimonio inmueble integrado con el mueble, es decir, que el edificio importa tanto como lo que en él se resguarda ${ }^{35}$. Adicionalmente, con base en criterios más bien geográficos, el Congreso discutió la ubicación ideal del Centro Cívico.

Así, el Arq. Rafael Ángel García, quien defendía su localización fuera del centro de San José y, por otro, la de la Oficina de Planificación (Nacional) y el Ing. Eduardo Jenkins ${ }^{36}$ del Departamento de Urbanismo del INVU, impulsor de la famosa "manzana" en un contexto cultural. En la llustración 4 puede observarse la distribución del Centro Cívico Gubernamental, idealmente planeada para albergar la institucionalidad pública. Cabe resaltar aquí que en el plano de 1964 no parecía haber conflicto en cuanto a la ubicación de la Biblioteca o la conservación del Edificio del Museo.

Por último, el Arq. Robles Aguilar, reconduce la discusión legislativa por criterios urbanísticos. Robles representa un avance en cuanto a la planificación urbana en Costa Rica, como lo demuestran sus argumentos: (i) interrelación física no significa una integración cultural-funcional (bibliomuseo) ${ }^{37}$; (ii) necesidad de estudios integrales de tipo urbanístico por encima de estudios técnicos individuales; (iii) incorpora el fin cultural de un conjunto como un criterio urbanístico; (iv) restringir por vía legal la ubicación del terreno antes del concurso implica un sesgo en la licitación; (v) falta de criterios técnicos a profundidad tanto sobre el área en cuestión como el fin del inmueble y del conjunto; 
Ilustración 4. Centro cívico gubernamental. Ing. Eduardo Jenkins. Fuente: ANCR. Serie Mapas y Planos. N051389. Año: 1964. su papel director en el Proyecto de Centro Cívico propuesto por el INVU en los años cincuenta. Entre sus ideas destaca la de impulsar un centro cívico político donde se incluyese a todos los poderes del Estado. El área cuarta, entonces, se apartó para "Poder Judicial (Corte Suprema, Juzgados y Alcaldías), en el área actualmente ocupada por la Universidad y según proyecto ya elaborado". En la sexta área, el "Grupo Cultural, que incluirá la Biblioteca Nacional, el Museo Nacional, posiblemente un teatro al aire libre o concha acústica, un auditorio de masas, etc." En: Jenkins. et al. (1956).

37 Sesión ordinaria de la Comisión

Permanente de Asuntos Sociales N057 de las 14h del cuatro de octubre de 1967.

38 Sesión N075, op.cit., f.5. Gutiérrez se opone a sus planteamientos: cuestiona su participación en el "foro universitario" y lo califica de dogmático y neófito en la materia. Con un tono un poco irónico, Robles defiende su postura dirigiéndose al Diputado como educador, al responderle que un Decano de una Facultad de Derecho estaría de acuerdo en la forma como deben construirse las bibliotecas.

39 Sesión N49, op.cit., f.10.

40 Decreto №7 del 20 de febrero de 1969.

$41 \quad$ No olvide el lector anotar que este cuadrante se ubica actualmente alrededor de Parque Nacional completado por el Tribunal Supremo de Elecciones, la Asamblea Legislativa y el Museo Nacional, entre otras cercanías notables como la Estación del Ferrocarril al Atlántico, la Antigua Aduana y el Edificio Solera.

$42 \quad$ Actualmente la Ley de Patrimonio

Arquitectónico №7555 de 4 de octubre de 1995 rige la materia patrimonial y cuenta con una Comisión

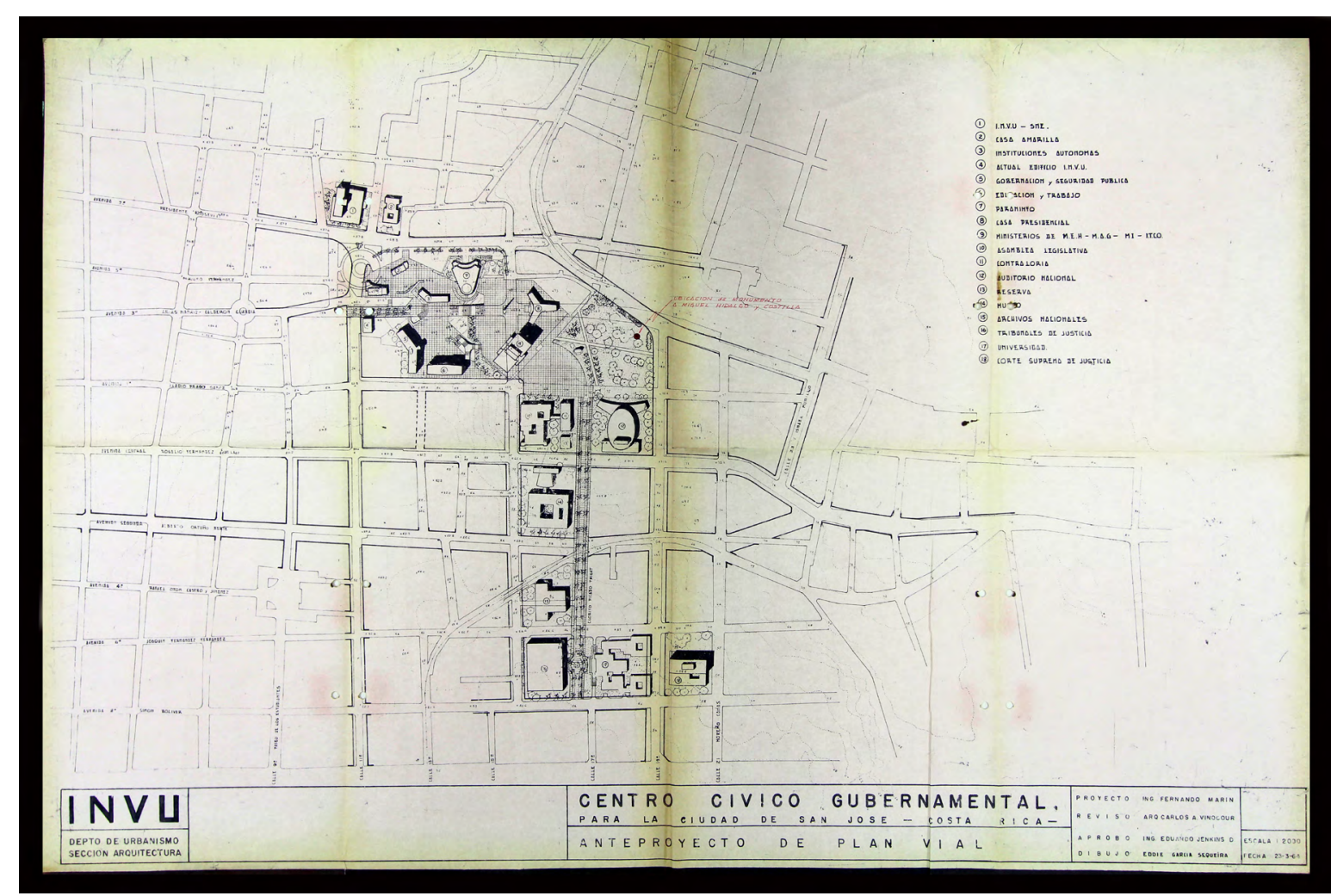

(vi) armonización nacional e internacional con base en criterios especializados; (vii) inconveniencia de imitar un modelo sin adaptarlo [mexicano]; (viii) necesidad de pensar en una arquitectura urbanística y (ix) planificación integral con proyección a cincuenta años, mínimo ${ }^{38}$.

Finalmente, dentro de la Comisión se optó por dar prioridad a la magnanimidad de una obra individual correspondiendo a su fin, el museístico. Sin embargo, por encima de estos y otros aspectos como los geográficos, continúa predominante en actas, una reiteración de los ideales de progreso y modernidad. Discutido el tema urbanístico, se publica el Proyecto de Ley, con la respectiva convocatoria para el concurso arquitectónico, dando resultado a lo que hoy se conoce como Centro Cívico. A manera de cierre, se transcriben algunos argumentos de Gutiérrez que dejan entrever la predominancia del fervor nacional progresista:

“...creo...que una simple adhesión sentimental a uno de los pocos edificios viejos no antiguos que tiene San José no debería ser obstáculo. Yo parto del criterio de que hay edificios antiguos y edificios viejos. En el edificio antiguo reconozco la dignidad de los siglos, para mi [sic] aunque no soy arquitecto, el edificio actual del Museo es un edificio viejo y no antiguo. El Museo Nacional estaría mejor servido si pudiera contar con alojamiento digno de sus colecciones y digno de la riqueza arqueológica y natural del país ${ }^{39 "}$.

\section{Conclusiones}

Como una especie de obituario del Patrimonio Urbano se publica en La Gaceta №44 del 21 de febrero de 1969 "que autoriza la inscripción registral del terreno que ocupará la nueva biblioteca". Es decir, se hacía público el derribo de la considerada vetusta edificación y se consagraba al dominio público de la nación ${ }^{40}$ el terreno que ocuparía una verdadera Biblioteca Nacional dentro de este cuadrante cívico ${ }^{41}$ que tan acalorada discusión generara en la Comisión de Asuntos Sociales de la Asamblea Legislativa de Costa Rica. Finalmente, el desenlace de este Expediente es la Ley N05232 del 16 de julio de 1973, la Ley para construir el Centro Cívico Nacional.

Aquí relatada la discusión legislativa, se intenta brindar nuevas luces para la comprensión de los problemas jurídicos de corte urbanístico y para ejemplificar por qué en Costa Rica ha prevalecido un modelo progresista sobre uno urbanístico, en detrimento de la arquitectura pública y privada. De igual forma puede aquí encontrarse nuevos conceptos para configurar el patrimonio arquitectónico urbano. El Centro Cívico se constituye en un referente para la dificultad de atribuir competencias en torno al patrimonio ${ }^{42}$, la reticencia política a la hora de tomar decisiones sobre criterios nacionalistas más que criterios técnicos poco halagüeños para el patrimonio. 
de Patrimonio adscrita al Ministerio de Cultura que decide las declaratorias de patrimonialidad, así como un Centro de Patrimonio para su investigación y conservación.

43 Vega Sibaja, op. cit. Antecedentes, p. B.
La visión del patrimonio urbano ha predominado en Costa Rica de tal suerte que aún en la década de los ochenta se haya desempolvado la lapidaria sentencia de la ciudad capital: "San José, salvo en excepciones, no tiene muchas áreas o edificios de interés histórico 0 arquitectónico. Si queremos darle 'carácter', por lo tanto, tiene que ser a base de diseño urbano, para crear conjuntos espaciales llamativos, parques, plazas, ejes visuales, sitos de convivencia y mobiliario urbano como gradas, postes, receptáculos de basura, bancas y fuentes, todo diseñado con sensibilidad artística"43.

Lo que otras generaciones resuelvan sobre la ciudad heredada y su patrimonio deberá sostenerse en el futuro y gestionarse adecuadamente por la siguiente generación. El Cuartel Bellavista sobrevive en el Centro Cívico como uno de los precedentes de la planificación en Costa Rica y como un recordatorio para el legislador del compromiso de preservar el patrimonio urbano para las futuras generaciones; donde el urbanismo, el derecho urbanístico, la cultura y la arquitectura no sean estratagemas sino indicadores del desarrollo.

\section{Referencias Bibliográficas}

Asamblea Legislativa de Costa Rica. Proyecto de Ley para creación de un centro cívico. Expediente №2970 de 12 de julio de 1967. En: Diario Oficial La Gaceta, San José, Costa Rica de 19 de julio de 1967.

Corrales, F. y Cubero G. (2005). De cuarteles a museos: los museos y el discurso de la civilidad costarricense. Cuadernos de Antropología, 15, 11-23.

Fernández, A. (3 de enero de 2010). La memoria perdida. La Nación. Recuperado de http://wvw.nacion.com/ancora/2010/enero/03/ancora2204620.html.

Fernández, A. (7 de febrero de 2010). Delito de lesa urbanidad. La Nación. Recuperado de http://wvw.nacion.com/ancora/2010/febrero/07/ancora2250508.html.

Jenkins, E. et al. (1956). El centro cívico de San José. En: Kayanan. A.C. (1955). Elementos propuestos para una ley básica de planificación en Costa Rica [y otros documentos para la planificación]. Inédito.

Muñoz, M. (1990). El estado y la abolición del ejército, 1914-1949. Editorial Porvenir.

Ruiz, N. (1973). Biblioteca Nacional Miguel Obregón Lizano. Tesis de Licenciatura en Ciencias y Letras. Facultad de Letras de la Universidad de Costa Rica.

Sistema Nacional de Bibliotecas (S/A). "Arquitectura para una historia: los edificios de la Biblioteca Nacional Miguel Obregón Lizano" [en línea]. San José: Vives, I. Disponible en: http://www.sinabi.go.cr/exhibiciones/subportalestematicos/ bibliotecanacional/BibliotecaNacional.aspx. Consulta: 9 de enero del 2016.

Vega, J. (1982). Centro cívico nacional y anillo de renovación urbana de San José. Tesis de Licenciatura en Arquitectura. Facultad de Ingeniería de la Universidad de Costa Rica.

\section{Leyes}

Ley N4574, Diario Oficial La Gaceta, San José, Costa Rica, 18 de mayo de 1974.

Constitución Política, Asamblea Constituyente, San José, Costa Rica de 7 de noviembre de 1949.

Decreto N7, Diario Oficial La Gaceta, San José, Costa Rica, del 21 de febrero de 1969. Ley N4788, Diario Oficial La Gaceta, San José, Costa Rica, de 17 de julio de 1971.

Ley N05232, Diario Oficial La Gaceta, San José, Costa Rica, de 16 de julio de 1973.

Ley N05397, Diario Oficial La Gaceta, San José, Costa Rica, de 8 de noviembre de 1973.

Ley N7555, Diario Oficial La Gaceta, San José, Costa Rica, de 20 de octubre de 1995. 
Ley N²4240, Diario Oficial La Gaceta, San José, Costa Rica, de 30 de noviembre de 1968.

Ley N01542, Diario Oficial La Gaceta, San José, Costa Rica, del 7 de marzo de 1953. 